\title{
Subjective Well-Being and Aversion to Macroeconomic Losses: New Evidence
}

\author{
David Patiño $^{1}$ D Francisco Gómez-García ${ }^{1}$ - Alejandro Marín-Serrano ${ }^{1}$
}

Accepted: 27 April 2021 / Published online: 20 May 2021

(c) The Author(s), under exclusive licence to Springer Nature B.V. 2021

\begin{abstract}
This work analyses the existence of asymmetric effects on the subjective well-being of the population of different countries in response to changes in the levels of aggregate income. Microdata from the Eurobarometer and the World Values Survey are used for the period 2000-2019. This period includes several economic changes, among which are the strong expansion at the beginning of the century, the Great Recession, and the subsequent recovery. Our study includes several groups of countries. In the broadest case, the study comprises a group of 83 countries and analyses the issue both from a global perspective as well as focusing particular attention on European countries. These asymmetric effects of economic activity are in line with behavioural economics and previous literature and allow us to determine a macroeconomic aversion to losses. The results obtained support the existence of asymmetric effects of changes in aggregate income on subjective well-being, and show that losses generated in recessions require a far more vigorous recovery if they are to be compensated for, and that they might even have permanent effects.
\end{abstract}

Keywords Subjective well-being $\cdot$ Business cycle $\cdot$ Asymmetric effects · Great recession · Life satisfaction

\section{Introduction}

The economic crisis that began in 2008 has had a strong impact on the whole of the European population. This has affected a large number of socio-economic indicators and, in a period where the Great Recession is taking place, it is worth asking whether individuals are more sensitive to macroeconomic losses than to macroeconomic gains. The question becomes much more relevant given the major recession that the Covid-19 crisis is causing and the paralysis that the containment measures have brought about. Although the two economic crises differ, our work can provide insights into certain mechanisms involved in this new economic-financial crisis. This article attempts to answer this question, using subjective well-being data to examine what effects macroeconomic conditions have on individuals and their situation, and in particular seeks to ascertain whether there might be

David Patiño

pato@us.es

1 Department of Economics and Economic History, University of Seville, Seville, Spain 
asymmetrical effects on individuals given that they do not react to recoveries and recessions in the same way.

There are several reasons for posing this question. Since Easterlin (1974), the links between happiness and income have become one of the axes of what has come to be called happiness economics. In addition, the crisis that began in 2008 has led to serious macroeconomic consequences in Europe, drastically reducing economic activity and entailing enormous social costs among the population by having a major impact not only on material but also on subjective as well as emotional aspects. This is so much so that some authors propose including indicators that measure subjective aspects of individual well-being in addition to the traditional ones that measure aspects related to economic growth (Apergis \& Georgellis, 2014). This work is based on the prospect theory (Kahneman \& Tversky, 1981), and seeks to relate macroeconomic aspects to individual ones, since the literature has highlighted the asymmetry of the impact of changes in the level of income on subjective well-being, depending on whether the change is positive or negative. Conclusions point to individuals' aversion to losses; in other words, that a negative variation in their income has a greater effect on well-being than a positive variation does.

This paper analyses how economic fluctuations have affected citizens' subjective wellbeing. To carry out this study, we analysed the evolution of a wide and varied group of countries around the world throughout the current century. We also study what happened in Europe between 2005 and 2017. In this way, we were able to analyse a period that encompasses a wide variability of specific situations that include periods of economic expansion, a deep economic crisis and other periods of development and recovery. Furthermore, the variability of countries, periods and samples allows us to study this issue from unprecedented perspectives. The work uses microdata on subjective well-being as well as socioeconomic factors from the Eurobarometer and, as a novelty, from the World Values Survey (hereinafter, WVS), in addition to aggregate data from World Bank and Eurostat, to specifically measure overall economic activity.

There is extensive literature exploring the effects of economic fluctuations on individuals' well-being, with studies highlighting that the deterioration of economic and financial indicators during periods of crisis has a profound effect on the population's well-being (Deaton, 2012). However, fewer studies have focused on the importance of various socioeconomic factors vis-à-vis subjective well-being, nor have they related individual and aggregate levels in different countries (see Gonza \& Burger, 2017). The literature has also looked at how economic and personal variables affect subjective well-being. In this regard, works such as Di Tella et al. (2003) and, more recently, De Neve et al. (2018) can be considered seminal. In particular, the latter conducts a thorough analysis of the question. The present work replicates said study by expanding its scope, both in the time interval studied and by including a database that the previous one did not consider. Specifically, Di Tella et al. (2003) does not cover the period that marked the onset of the crisis in 2008. For their part, De Neve et al. (2018) span a long period that concluded in 2013, therefore it includes the worst moments of the recession although it does not allow analyzing the subsequent recovery. In this way, our work broadens the analysis to 2019 and studies the changes that might have triggered a recession as deep as the one to occur in the 2008-2013 period. This allows us to test whether the tendency found in the above-mentioned work is robust to such a high seizure. Taking the EU as a reference, although not focusing exclusively thereon, this work uses a database not considered in the above-mentioned work (World Values Survey).

By considering the expansionary path of the first decade of the twenty-first century, the Great Recession and the Recovery in the second half of 2010, we are able to capture 
a period of considerable interest. The two databases used endow the work with substantial robustness. Furthermore, we consider that by providing a theoretical model (a central reference for the subsequent implementation of our microeconometric model), we increase the logical coherence of the explanation. This explanation comes from behavioural economics and its empirical demonstration that individuals do not follow the axiom of homo economicus when making decisions in the presence of uncertainty. According to the majority approach, in these circumstances individuals maximize the expected utility, as posited by von Neumann and Morgenstern (1944), which leads them to value, in absolute terms, losses and gains in the same way. Yet, as demonstrated by Kahneman and Tversky (1974, 1981), and by subsequent literature, individuals are averse to losses and therefore display biases against them when making their decisions. This paper argues that this idea is not only valid in microeconomic decisions. On the contrary, it can also explain that the results of economic activity, positive or negative, affect individuals differently, or at least how they perceive the consequences of those results.

It is possible to find empirical literature which reports that fluctuations in economic activity do not have a symmetrical effect on individuals' subjective well-being. In particular, it has been found that downturns in economic activity have a greater impact than upturns (Baumeister et al., 2001). Although few works have addressed the topic, they have shown that negative variations in GDP have a greater effect on individuals' subjective well-being than positive ones. Bonasia et al. (2018) also study a group of European countries, but use data from countries grouped on average, and dispense with microdata analysis. Beja (2017) uses a similar methodology to the one used in this work, although his study focuses on income variations and delays, obtaining similar conclusions regarding their asymmetric effects on the population's welfare. Our paper seeks to extend the scarce extant literature dealing with the effects which the economic cycle has on individuals' happiness by analysing the outcomes from different perspectives; specifically, we use periods of growth and downturns in economic activity to analyse what effect they have on individuals' self-declared well-being. Additionally, our research also tests whether the results found by behavioural economics at the micro level remain valid when considering the macro level.

Exploiting happiness data in European countries to study the crisis period has been more common. Works which have followed this line have determined that this economic recession has led to significant falls in well-being levels for citizens, albeit with major differences between them. For example, Mertens and Beblo (2016) point out that different levels of labour rights protection have triggered considerable differences between European nations. Other documents have focused on studying specific countries, such as Ireland (Weckroth et al., 2017). Other authors have centred their attention on countries in the European periphery (Guardiola \& Guillen-Royo, 2013). Our work focuses on a broad sample of European countries (27), but also broadens the study of the subject from a global perspective in a new way, including a very large group of countries from all regions of the world.

The article is structured in four sections, in addition to this introduction. The first provides a theoretical basis for the hypothesis of asymmetry in the valuation of gains and losses, which was seminally put forward by Kahneman and Tversky, and whose empirical testing at the macro level represents the main contribution of this paper. The following section describes the data used and the study methodology. Specifically, it indicates the origin of the various sources of both micro and macroeconomic data, the main characteristics thereof and the principal variables used in the work. The fourth section provides the results and comments on them through the microeconometric methodology used. The article ends with a series of 
conclusions derived from the analysis carried out as well as an approach to some possible extensions of the analysis.

\section{Relationship Between Economic Activity and Subjective Well-Being: Theoretical Framework}

The study of biased preferences generated by loss aversion derives from Kahneman and Tversky's (1981) prospect theory. These two authors developed this view as a reaction to von Neumann and Morgenstern's theory of expected utility (1944). Kahneman and Tversky consider that the theory of expected utility falls within the group of ideal models of people's behaviour, but that it fails to accurately describe human behaviour. Rather than seeking to maximize expected utility, individuals first and foremost feel an aversion to loss, and this different evaluation of gains and losses shapes their behaviour in many situations. The prospect theory modifies the focus of attention, moving it from levels of wealth to changes therein and introducing relativity in behaviour valuation that depends on the starting point. It holds that, when there are losses, the utility function decreases more rapidly than when there are gains.

The fact that individuals make their decisions with bias breaks with the conventional view that they maximize their expected utility and that they evaluate it, in the same way, at any income level. In contrast, bias makes the evaluation dependent on the level of income that the individual has and leads people to different paths of evaluation which evolve depending on the changes that occur therein. In short, unlike the traditional view, the individual's endowment determines their results.

The conventional utility function governs the satisfaction which individuals achieve when they satisfy their needs, via consumption, through certain quantities of goods. In this sense, income provides that satisfaction in that it enables people to acquire goods. The behaviour of a consumer who acts with such rationality is modelled through decreasing demand curves, fulfilling a series of conventional mathematical conditions. Consumer behaviour is described by giving utility values to each quantity of goods consumed in which higher values of the function are preferred. Figure 1 shows a representation of the conventional utility function (A), together with another which includes the loss aversion bias corresponding to function $\mathrm{B}$.

From this approach we develop our assessment of the asymmetric effect of changes in economic activity based on the theory of expected utility which will serve as a theoretical approach to our method. Using self-reported welfare data, we can use the utility function shown in Eq. 1:

$$
U\left(B_{j}, X_{j i}\right)
$$

where $U$ represents the level of utility obtained, $B_{j}$ the variation of income in the country $j$, and $X_{j i}$ the remaining socio-economic characteristics of individuals and the country in which they reside. The possible asymmetric effects of the evolution of economic activity, and in particular loss aversion, makes the relationship fit more adequately through the function expressed in Eq. 2:

$$
U\left(B_{j}^{+}, B_{j}^{-}, X_{j i}\right)
$$

where what is relevant is the variation in income, both in terms of its sign and the amount of the variation. Specifically, $B_{j}^{+}$represents a growth in the level of income of country $j$ 
Fig. 1 Comparison between the classical utility function and that of Kahneman-Tversky. Source: Own elaboration based on Kahneman-Tversky (1981)

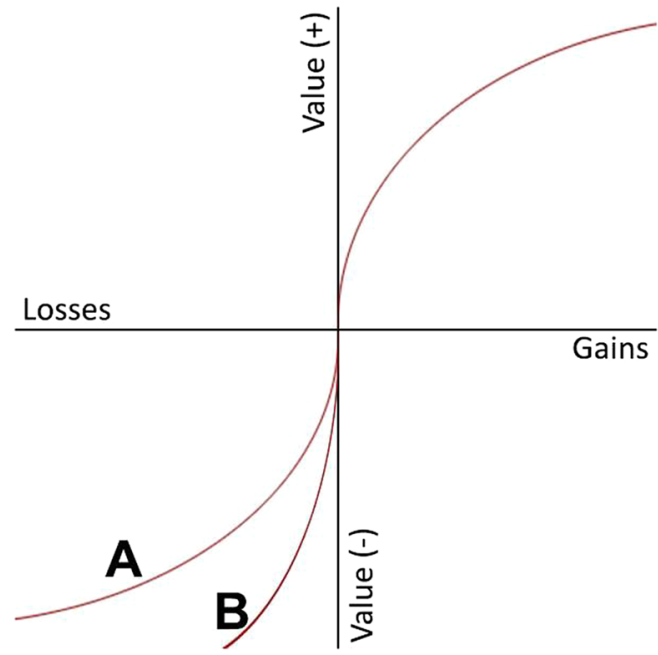

Source: Own elaboration based on Kahneman-Tversky (1981)

with respect to the previous year's level, and $B_{j}^{-}$a variation, in this case a decreasing or negative one. This division responds to the asymmetric impact that each one of these variations would have on the welfare function. This work measures what effect economic activity has on individuals, considering these income variations. Economic activity is measured from the variation in GDP, considering its increases and decreases separately. Variations in the economic situation impact the individual's well-being mainly through individual income but also through other variables such as expectations regarding the future, or uncertainty. ${ }^{1}$ These elements make up the individual's utility function and are included together with personal aspects as controls.

Following the works of Krueger and Schkade (2008) or Hirschauer et al. (2015), the hypothesis we therefore test involves analysing the relationship between individuals' utility - approximately their satisfaction with life—and economic activity, differentiating rises and falls in the level of aggregate income, and controlling through various relevant personal and institutional categories, as set out in Eq. 3:

$$
S V=U\left(B_{j}^{+}, B_{j}^{-}, X_{j i}, Y_{j i}\right)+\varepsilon_{j i}
$$

where $Y_{j i}$ is the vector of socio-economic aspects of the individual in the country, in which the individual studied resides. In short, we measure the impact of economic fluctuations on the well-being of individuals as they perceive it and from the assessment they themselves make, explicitly, on their life at the time they are asked.

\footnotetext{
1 By testing the hypothesis that individuals experience boom and bust differently, we test something similar to the prospect theory in the macroeconomic setting.
} 


\section{Data and Methodology}

To test the hypothesis set out in the previous section, we mainly use microeconomic data, which include a measure of the utility or well-being that individuals have at each moment. Welfare levels are measured through the answer given to the question concerning their level of satisfaction with life as a whole. In addition, we require the main individual factors that explain those answers. These factors are then introduced into the model as individual controls of the levels of satisfaction with life. We use the factors identified in the literature as important determinants of life satisfaction and that explain it in part. Finally, we introduce indicators of changes in the level of aggregate income, distinguishing between positive and negative growth. Finally, the model captures the peculiar characteristics of the countries in which individuals reside in order to eliminate the effect that such characteristics have on the well-being reported by individuals.

The main difficulty in terms of data lies in the microeconomic database, which includes socio-economic data from a large number of individuals, and which provides us with relevant information. There are two databases that meet these requirements and which allow us to analyse a time interval that includes sufficient variability in economic activity. In addition, drawing on a large number of countries allows us to increase the variability of the variable whose effect we seek to measure. Specifically, the standard edition of the Eurobarometer ${ }^{2}$ and World Values Survey constitute two surveys with a sufficient number of waves and countries to carry out the exercise and, therefore, constitute the empirical base used in this work. The work adopts a global perspective, although it focuses particular analysis on the group of European countries that belong to the $\mathrm{EU},{ }^{3}$ since they share similar institutional characteristics. However, we also study other European countries and other regional areas. Overall, we have amassed a large number of observations, both individually as well as in terms of countries and periods. Likewise, the two surveys were required in order to provide information that would be as homogeneous as possible, ensuring the surveys had the same or very similar variables, thereby enabling the same model to be estimated in both cases. With some exceptions, which will be discussed in the next section, the objective of the samples used has been met. However, certain considerations should be taken into account when comparing the results.

In this sense, one prominent feature is that the Eurobarometer provides the necessary data continuously for the whole group of selected countries. In addition, the Eurobarometer carries out two annual waves that have included all the relevant variables since 2005 . Therefore, we have taken a period that can extend from that year until 2017. This period includes the last expansionary years of the first decade of the century, the Great Recession and the subsequent recovery. In total, 691,781 observations from 27 European countries have been used from this source. In addition, we have also carried out the analysis with annual variations in GDP and only one of the waves, thereby increasing the number of countries included to 34 in a total of 398,471 observations.

\footnotetext{
2 The "Standard \& Special Eurobarometer" section was established in 1974 to periodically analyse and synthesise public opinion on a wide variety of topics of interest in European Union member countries, through face-to-face and telephone surveys. It is the largest programme of temporary and geographical opinion surveys. Standard modules focus on individual population trends, such as satisfaction with life, work and family conditions.

3 The United Kingdom formed part of the EU throughout the whole of the period during which the study was carried out.
} 
The World Values Survey (Inglehart et al., 2014) includes countries from all over the world, among which are the majority of those that make up the EU. This survey is conducted regularly around the world by an independent association. It includes both a longer time horizon and a more heterogeneous group of countries than the Eurobarometer. This survey covers the period from 1981 to 2019, although it does not include all the years of the period. Furthermore, with the available macroeconomic data, the period in which estimates can be made is limited to 2000-2019, with the exception of 2015, which is not available. WVS includes a group of 83 countries for which we have all the necessary data, including $15 \mathrm{EU}$ countries as well as a further 14 European countries. In total, the number of observations used in the more general model amounts to 179,329.

The work thus focuses on the period comprised in the two decades of the current century. This period includes a phase of strong growth, the first decade of the twenty-first century, periods of recession such as 2000-2001 and, mainly, the period of the Great Recession (between 2008 and 2013) as well as stages of moderate growth, such as the subsequent recovery that lasted until the onset of the pandemic. This time interval allows us to examine a substantial variability of economic activity in order to analyse its effect on individuals. In comparison to other previous works that have addressed the subject, our work makes an important contribution by extending the period analysed.

The endogenous variable is constructed from respondents' responses to the question on satisfaction with life. There are three dimensions of subjective well-being: evaluative, hedonic, and eudaimonic (Graham \& Nikolova, 2015). Evaluative well-being refers to an assessment, made by the interviewee, of the degree to which they are satisfied with their life as a whole. Hedonic well-being refers to the emotional and affective component of subjective well-being. This concept reflects how people experience their lives versus how they value them more generally (Kahneman \& Krueger, 2006). Finally, eudaimonic well-being reflects the Aristotelian notion of happiness as a vital purpose and focuses on the flourishing and fulfilment of human potential (OECD, 2013). ${ }^{4}$ Tay and Diener (2011) find that, compared to the other two dimensions, life satisfaction is more associated with macroeconomic conditions at the country level.

Taking this into account, the evaluative dimension of subjective well-being is adequate for the objective of our article. This dimension corresponds to a question that is repeated in the two surveys we use, with a very similar formulation, such that it may be considered equivalent. Specifically, in the Eurobarometer the question is:

On the whole, are you very satisfied, fairly satisfied, not very satisfied or not at all satisfied with the life you lead?

In WVS the question is.

All things considered, how satisfied are you with your life as a whole these days (nowadays)?

The main difference between the two surveys lies in the number of possible responses. In the Eurobarometer, it is answered using a scale between 1 and 4, together with a 5 that is "Don't know", where 1 is "Very satisfied" the highest possible level of life satisfaction, and 4 "Not at all satisfied" the lowest. In contrast, the scale in WVS ranges from 1 (Dissatisfied) to 10 (Satisfied). In our estimations, we take the "don't know" answers, does not respond or refuses to answer as missing and, in the case of the Eurobarometer, rescale the answers so that they are increasing, so that 4 now represents the highest satisfaction, and can thus

\footnotetext{
${ }^{4}$ See Stone and Mackie (2013) for a discussion of these three dimensions of subjective well-being and the interactions between them.
} 
Table 1 Average annual satisfaction with life in the Eurobarometer and WVS. Source: Own elaboration based on GESIS data (several years) and Inglehart et al. (2014)

\begin{tabular}{lll}
\hline Year & Eurobarometer & WVS \\
\hline 2000 & & 2.448 \\
2001 & & 1.927 \\
2002 & & 1.895 \\
2003 & & 2.378 \\
2004 & & 2.185 \\
2005 & 2.908 & 2.484 \\
2006 & 2.924 & 2.248 \\
2007 & 2.923 & 2.145 \\
2008 & 2.880 & 1.935 \\
2009 & 2.869 & 1.666 \\
2010 & 2.877 & 2.409 \\
2011 & 2.859 & 2.269 \\
2012 & 2.811 & 2.389 \\
2013 & 2.818 & 2.233 \\
2014 & 2.891 & 2.296 \\
2015 & 2.913 & \\
2016 & 2.923 & 1.824 \\
2017 & 2.959 & 2.343 \\
2018 & & 2.451 \\
2019 & & 2.238 \\
Average & 2.889 & 2.198 \\
\hline
\end{tabular}

be interpreted more easily. The two surveys are not directly comparable, but do allow us to analyse the robustness of the relationship between economic growth and life satisfaction. Therefore, given the exact non-comparability of the estimated values of the coefficients, the main conclusions should be based on the analysis of the signs and the degree of significance of the coefficients. However, in order to correct this problem to some extent, we have also performed the estimates with a variable that converts the WVS responses to 4. To do this, we have made an artificial categorization of the responses using quartiles, as is often done in the literature (see, for example, DeCoster et al., 2011).

Additionally, including WVS allows us to ascertain whether there are any differences with the results found by De Neve et al. (2018), who do not use this database. Specifically, it allows us to examine whether any differences are found with the Gallup World Poll, the basis on which they ground their global study and which includes a group of countries that is comparable to the one used in our work.

Table 1 presents the average annual life satisfaction in the countries studied for the years of the period, distinguishing the survey considered. For the Eurobarometer, the columns show the reported values, and for WVS those obtained after subjecting them to artificial categorization. As can be seen in the table, the values reported in the Eurobarometer are higher on average. In addition to the data processing effect, this can be explained by the different group of countries included in each of the surveys. Specifically, WVS includes certain countries that have low and very low income levels.

Both the Eurobarometer and the WVS also allow the variables used to introduce the required individual controls to be determined. Through these variables, which 
the literature has pointed to as being determinant of the levels of satisfaction, different socio-economic characteristics of the individuals interviewed are measured. The variables included comprise the main determinants of subjective well-being indicated in the literature (Radcliff, 2013). Specifically, age, gender, marital status, number of years of education, employment situation, size of the population nucleus in which the interviewee resides and whether they have children aged 10 or under are included. The only difference is that the WVS includes a subjective assessment of individual income, through a question put to respondents. The Eurobarometer does not collect this variable. However, educational level is strongly correlated with that of income and adequately predicts the latter, albeit in conjunction with the specific effect of education. Insofar as it is included to control its effect, we can consider the model to be properly specified. Education is measured in the Eurobarometer through the number of years of studies completed ${ }^{5}$. In the case of WVS, dummy variables of the highest educational level attained have been included. The categorical variables were dichotomised into each of their categories in order to facilitate the interpretation of the results. Age is included continuously and is also introduced squared so as to analyse how the relationship between this variable and life satisfaction evolves. Whether the survey corresponds to the spring or autumn wave is also controlled.

Satisfaction with life also depends on the characteristics of the country in which the individual resides. Choosing a group of countries from the same geographical area guarantees us a certain institutional homogeneity, although there are substantial differences between them. Furthermore, the WVS does not include all EU countries, whereas the Eurobarometer does. However, using macroeconomic variables is complicated because we also use microdata. On the one hand, it is interesting to capture the socio-economic particularities of the countries in which the individuals live. On the other hand, in order to do so we would have to introduce a set of variables that would be identical for each country and each period in all the corresponding observations, and these variables are likely to be correlated with each other. From another perspective, many socio-economic characteristics vary very slowly and are structural, although those relating to the welfare state have been able to do so throughout the cycle, due to the policies of cutbacks applied in the countries in crisis. For all these reasons, it was decided to capture these differences through a dummy of the individual's country of residence. In this way, it is possible to capture not only all the institutional but also the social idiosyncrasies of each country. Likewise, a dummy is introduced showing the period of time in which the survey was carried out. We understand that through these variables we are able to capture the structural and contextual aspects, in addition to variations in GDP, which explain satisfaction with life in order to gauge what effect this latter variable, which provides the focus of this work, might have. In this way, our calculations are more comparable to other studies and avoid the complex bidirectional causal relationships between macroeconomic variables and economic growth indicated by De Neve et al. (2018) .

\footnotetext{
5 This variable assigns an arbitrarily high value to denote students. This value has been replaced by the individual's age minus 3, the age at which the educational system is accessed in most European countries.

6 We have not found clear and robust effects of other variables. Specifically, inflation has been found statistically significant in the Eurobarometer without finding any effect of unemployment. Instead, the unemployment rate is statistically significant in WVS while inflation has no influence. A more in-depth analysis of these factors can be found in De Neve et al. (2018).
} 
Table 2 Summary of the main descriptive statistics of the samples used in this work. Source: Own elaboration based on Eurostat data (2020) and GESIS (various years), World Bank (2020) and Inglehart et al. (2014))

\begin{tabular}{llllll}
\hline Variables & $(1)$ & $(2)$ & $(3)$ & $(4)$ & $(5)$ \\
& $\mathrm{N}$ & Mean & SD & Min & Max \\
\hline Year (Eurobarometer_Eurostat) & 691,781 & 2.011 & 3.747 & 2.005 & 2.017 \\
Year (Eurobarometer_World Bank) & 179,329 & 2.011 & 5.907 & 2.000 & 2.019 \\
Year (WVS_World Bank) & 691,781 & 2.011 & 3.747 & 2.005 & 2.017 \\
Positive GDP growth. Eurostat & 691,781 & 2.626 & 2.693 & 0 & 24.467 \\
Negative GDP growth. Eurostat & 691,781 & 0.739 & 2.096 & 0 & 16.80 \\
Positive GDP growth. WB & 398,471 & 2.715 & 2.678 & 0 & 25.16 \\
Negative GDP growth. WB & 398,471 & 0.649 & 1.918 & 0 & 14.81 \\
Positive GDP growth. WB & 179,329 & 4.374 & 2.841 & 0 & 16.67 \\
Negative GDP growth. WB & 179,329 & 0.393 & 2.523 & 0 & 24 \\
\hline
\end{tabular}

The descriptive statistics of all the variables used in the main estimations can be consulted in Table A1 and Table A2 of the online annex

Table 2 contains the descriptive statistics of the variables used in the main estimate. In various columns, the table shows the values of the individual variables included. The variation in GDP, differentiating between growth and recession periods, constitutes the most relevant independent variable of the model (which is key to testing the initial hypothesis designed from the theoretical model). Given that the Eurobarometer surveys have been taken from two periods of the year, we needed four-month data for the European countries. These data come from Eurostat (2020). Specifically, the GDP figures by quarter have been taken in chain-linked volumes valued in 2010 euros, with data taken without adjustments for seasonality or calendar. The percentage variations have been taken with respect to the same quarter of the previous year, using the variations referring to the second and fourth quarters of the estimates. In estimates based on WVS that include non-European countries, we have used the World Bank's GDP variation data. Specifically, annual GDP figures for 2010 in US dollars have been taken. Likewise, we have also used this source in estimates which use only one annual wave in the Eurobarometer.

Equation (4), which corresponds to the main model of De Neve et al. (2018), reflects the aspects raised and specifically allows an empirical estimate of the hypothesis we posit. The dependent variable is individuals' satisfaction with life in general.

Specifically, the model we estimate is the following:

$$
Y_{i j t}=\alpha+\beta_{1} V P_{j t}^{+}+\beta_{2}\left|V P_{j t}^{-}\right|+\varphi_{i j t}+\omega_{j}+\vartheta_{t}+\varepsilon_{i j t}
$$

where:

The dependent variable $Y_{i j t}$ represents levels of satisfaction with life expressed by individual $i$ in country $j$ in year $t$.

$\alpha$ is the constant. 
$V P_{j t}^{+}$measures the percentage change in the GDP of country $j$ in year $t$ when it is positive, otherwise taking the value zero.

$\left|V P_{j t}^{-}\right|$measures the percentage change in the GDP of country $j$ in year $t$ when it is negative, and takes the value zero otherwise. This variable is taken as an absolute value to facilitate the estimation and interpretation of the coefficient.

$\varphi_{i j t}$ is the vector of individual characteristics relating to individual $i$ in country $j$ during year $t$.

$\omega_{j}$ are the fixed place effects for country $j$.

$\vartheta_{t}$ are the fixed time effects for year $t$.

$\varepsilon_{i j t}$ is the random disturbance.

Fixed country and year effects are included in order to analyse the results of their coefficients and thus control for heterogeneity between countries and periods by eliminating potential omitted variables that are specific to each territory, such as cultural or climatic differences.

The answers to the question about the valuation of life satisfaction are of a qualitative nature and define a variable which is the endogenous variable in the model and which has four possible categories in the Eurobarometer and 10 in the WVS, as previously indicated.

The literature employs discrete choice models to estimate explanatory models for this type of variable. However, there is sufficient empirical evidence (Ferrer-i-Carbonell \& Frijters, 2004; van Praag \& Ferrer-i-Carbonell, 2006) to suggest that an estimation using ordinary least squares is adequate under the assumptions of cardinality and normality of distribution, added to which it also facilitates the interpretation of the coefficients. Therefore, we use an estimation by ordinary least squares that is robust to heteroskedasticity taking twoway clusters, in our case of the country where the interviewee resides and the year to which the observation corresponds ${ }^{7}$. However, the main model has also been estimated using an ordered probit as a robustness check.

The work includes a large group of countries from the five continents with very heterogeneous characteristics. However, we study mainly Europeans since they are the only ones included in the Eurobarometer as well as in many of those included in the WVS. Likewise, a series of robustness checks have been carried out that estimate the same model for different subgroups of countries and regions. The time period analysed in the main model varies depending on data availability. In the case of the Eurobarometer, it includes the one between 2005 and 2017, an interval for which there are two surveys for the same year, one for spring and one for autumn. The same period is used for Eurobarometer estimates made with annual changes in GDP. For these calculations, World Bank data have been used in the same way as with the WVS. The availability of WVS data allows the period to be extended. Specifically, the period 2000-2019 is used although, as pointed out, 2015 is not included because it is not available.

\footnotetext{
${ }^{7}$ Different types of clusters have been tested. In general, the main results remain unchanged. The two-way cluster adequately fits the way the waves are grouped (different people because they are in different countries or in different years).
} 
Table 3 Effect of positive and negative changes in GDP on individual life satisfaction. Source: Own elaboration based on Eurostat data (2020) and GESIS (various years), World Bank (2020) and Inglehart et al. (2014)

\begin{tabular}{lll}
\hline Variables & $(1)$ & $(2)$ \\
& Eurobarometer-EU27 & WVS-All countries \\
\hline Positive GDP growth. WB & $0.00426^{* *}$ & $0.0536^{* *}$ \\
& $(0.00212)$ & $(0.0220)$ \\
Negative GDP growth. WB & $-0.0149^{* * *}$ & $-0.209^{* * *}$ \\
& $(0.00410)$ & $(0.0683)$ \\
Observations & 346,207 & 179,329 \\
\hline
\end{tabular}

Robust standard errors in parentheses, adjusted for clustering at the country-year level

$* * * p<0.01, * * p<0.05, * p<0.1$

\section{Results/Findings}

Table 3 shows the coefficients of the main variables in the equation that explains life satisfaction from variations, both positive and negative, in GDP and which differentiates, by columns, those obtained for each of the two surveys used. In the case of the Eurobarometer, only the autumn wave is considered with annual data from the World Bank and it analyses countries that make up the EU27 ${ }^{8}$. The differences in the value of the coefficients for the estimates reflect that the endogenous variable satisfaction with life in WVS varies among ten possible values and includes all the countries for which we had data. The first thing that stands out is that the estimated coefficients of economic activity, both positive and negative variations, are statistically significant when explaining individuals' satisfaction with life.

The table shows the asymmetrical effect of the variations in economic activity as pointed out by the theoretical model. Specifically, the value of the coefficients shows the impact that a positive or negative growth of one percentage point in economic activity has on the numerical value that individuals assign to the question about satisfaction with their life in general. In other words, similar to microeconomic behaviour, individuals are loss averse, in the sense that adverse economic situations have a greater effect than economic recoveries. Recessions cause a loss of life satisfaction in individuals that is greater than their failure to recover from economic expansions. In addition, our estimate for the 27 countries considered in the Eurobarometer and the 83 in the WVS quantifies this difference at being twice

${ }^{8}$ We include the UK as it formed part of the EU during the study period. 
as much or slightly more in both results ${ }^{9}$. Our results thus find that individuals' aversion to macroeconomic losses is as high as that assumed in their daily decision-making. Regardless of that value, it seems clear that loss of welfare in the group of countries considered, at least as reported by those assessing their situation, and which is caused by recessions in subjective welfare, is not atoned for by improvements in the situation triggered by recoveries in economic activity. This can be seen as evidence that individuals' aversion to macroeconomic losses appears to be both a European and a global phenomenon.

These results are similar to those identified in De Neve et al. (2018). Specifically, in the case of the results obtained from the Eurobarometer, the order of magnitude is almost identical, with an effect of negative changes that is 3.5 times higher than the effect of positive changes in GDP, with both being statistically significant. In the main model of De Neve et al. (2018) this proportion is 6.4 times. When we expand the group of countries, we find greater differences since this work, unlike our estimate shown in Tables 3 and 4, finds no statistically significant positive variations in GDP. It should be noted that we compared the

Table 4 Effect of positive and negative changes in GDP on individual life satisfaction. Robustness check with Ordered Probit estimation. Source: own elaboration based on Eurostat data (2020) and GESIS (various years), World Bank (2020) and Inglehart et al. (2014)

\begin{tabular}{lll} 
Variables & Eurobarometer-EU27 & WVS-All countries \\
\hline Positive GDP growth. WB & $0.00773^{* *}$ & $0.0257^{* *}$ \\
& $(0.00338)$ & $(0.0107)$ \\
Negative GDP growth. WB & $-0.0207 * * *$ & $-0.101 * * *$ \\
& $(0.00598)$ & $(0.0321)$ \\
Observations & 346,207 & 179,329 \\
\hline
\end{tabular}

Robust standard errors in parentheses, adjusted for clustering at the country-year level

$* * * p<0.01, * * p<0.05, * p<0.1$

\footnotetext{
9 The results are similar, at least in qualitative terms, if we estimate the variable satisfaction with life when modified so that it has four values and is comparable to that of the Eurobarometer. Specifically, the estimated coefficients in this case are those indicated in the table.
}

Variables

WVS-Life

Satisfation 4 values

Positive GDP growth. WB.

$0.0253 *$

(0.0138).

Negative GDP growth. WB. $-0.0920^{* *}$ (0.0404).

Observations. 179,329 .

Robust standard errors in parentheses, adjusted for clustering at the country-year level.

$* * * p<0.01, * * p<0.05, * p<0.1$

As can be seen, the estimated coefficients have a lower value compared to those in Table 3 . This reflects the lower variability of the endogenous variable, which now has only four possible outcomes. However, the orders of magnitude reflect the same differences as when we took the 10 values of the original variable from the survey. 
Table 5 Effect of positive and negative changes in GDP on the life satisfaction of individuals in European countries. Source: Own elaboration based on Eurostat data (2020) and GESIS (various years), World Bank (2020) and Inglehart et al. (20144)

\begin{tabular}{llll}
\hline Variables & $(1)$ & $(2)$ & $(3)$ \\
& $\begin{array}{l}\text { Eurobarometer-Euro- } \\
\text { stat_European countries }\end{array}$ & $\begin{array}{l}\text { Eurobarometer-WB-W } \\
\text { European countries }\end{array}$ & $\begin{array}{l}\text { WVS- } \\
\text { European } \\
\text { countries }\end{array}$ \\
\hline Positive GDP growth. Eurostat & 0.00192 & & \\
Negative GDP growth. Eurostat & $(0.00183)$ & & \\
& $-0.0121^{* * *}$ & & 0.0190 \\
Positive GDP growth. WB & $(0.00302)$ & 0.00311 & $(0.0151)$ \\
Negative GDP growth. WB & & $(0.00196)$ & $-0.0473^{* * *}$ \\
& & $-0.0150^{* * *}$ & $(0.0122)$ \\
Observations & 691,781 & $(0.00391)$ & 72,244 \\
\hline
\end{tabular}

Robust standard errors in parentheses, adjusted for clustering at the country-year level $* * * p<0.01, * * p<0.05, * p<0.1$

results obtained in different databases; Gallup and WVS. In any case, both results go in the same direction, and the changes in the bases or the periods analysed do not seem to produce any differences in the main conclusions.

Table A3 in the online appendix shows the estimated coefficients for the other variables included in the model as controls. Since many of the controls have been introduced as dichotomous indicators, many are estimated with reference to some specific value. This is the case of the indicator variables for the year and country. Satisfaction with life diminishes with age, albeit at a decreasing rate, since the coefficients of age, with a negative sign, and age squared are significant. Furthermore, men report lower life satisfaction than women. Years of education or having a university education increase the value reported. Income and working conditions, also in line with the literature, have a prominent effect. The strong negative effect of unemployment stands out, as does the powerful positive impact of income. Family circumstances also exert a significant impact. Specifically, being either divorced or separated, which is the one taken as a reference, has a clear negative effect. It contrasts with the situation of married people, who are those who report the highest levels of well-being. Finally, the type of residential habitat (type of community) has a negligible effect.

Table 4 shows estimates of the same model, although, given the qualitative nature of the endogenous variable, it uses an ordered probit model.

As can be seen, the estimation generates qualitatively similar results which are, therefore, robust to the estimation method. ${ }^{10}$ In addition, the asymmetry in the effects of variations in economic activity is maintained when we modify the data set used or restrict it to different groups of countries. For example, Table 5 estimates the defined model including all the European countries for which both the Eurobarometer and the WVS provide data. In the case of the Eurobarometer, the exercise is carried out in two different ways: on the one

\footnotetext{
${ }^{10}$ Results are also similar, and therefore robust, for all countries and for Europe, when we use a time trend instead of using a dummy variable for each year.
} 
hand, it uses data from the two annual waves, for the available years, while on the other, it is limited only to the autumn wave, as in Table 3.

As can be seen in Table 5, when we consider the largest group of European countries, the asymmetry still holds, although in this case, only the negative variations differ significantly from 0 . In contrast, when economic activity grows, there is no impact on the evaluation that individuals make of their life satisfaction as a whole. This result is also obtained when the WVS values are limited to the European countries for which it provides data, during the period 2000-2019, which is the one used in Tables 3 and 4. This result could indicate an even more pronounced asymmetry than the one highlighted in Table 3, and suggests that recessions could be triggering irretrievable or structural losses in the valuation of people's lives. ${ }^{11}$

\section{Conclusions}

This article shows the asymmetrical effects of variations in economic activity on their impact on individuals' stated life satisfaction. In particular, we find that downturns in economic activity have a greater impact than upturns. This conclusion is drawn from different samples of several hundred thousand observations of citizens, during a period characterized by highly volatile economic activity. Specifically, a period is analysed that covers the strong expansion at the beginning of the century, the Great Recession which commenced in 2008, and the subsequent recovery. The results have been found to be robust to a series of modifications that include the estimation method, the group of countries considered or how the conjuncture is controlled.

In the most general result, it can be seen that the differential effect is clearly higher in absolute terms, which allows us to relate our results to the loss aversion experienced by individuals, as highlighted by behavioural economics. However, above all, our results highlight the effect that recessions have on the subjective valuation that individuals make of their lives. In this sense, they confirm the results obtained by De Neve et al. (2018), which are now confirmed with new databases and an extended period, and highlight the need to continue exploring what effect economic activity, and macroeconomic aspects in general, have on the well-being of individuals.

This result can be of great relevance, since it points out certain effects of economic cycles that had not, to date, been sufficiently considered by the literature. When the consequences of recessions are listed, the loss of production is included and its irretrievability is noted, as are the economic -and even psychological- effects of unemployment, which are often permanent. However, our results indicate that recessions can have an effect on the well-being of individuals that is very difficult to recover from. Drawing a comparison with production, it can be said that recessions trigger an irretrievable loss of well-being. In addition to its intrinsic importance in terms of subjective welfare, this allows us to pinpoint important costs, even in economic terms, such as depressions and other adverse effects on the population beyond those usually highlighted (Case \& Deaton, 2017). The literature on the economics of happiness has found evidence that unemployment has a significant permanent effect on the lives of those affected. Our results indicate that the emotional costs may run deeper and may affect those who suffer from it in a general way, rather than merely impacting the groups most affected by the recession. In this sense, it is worth

\footnotetext{
11 Similar results were found when the study was repeated, limiting those European countries that suffered some type of intervention during the Great Recession. On the other hand, similar results have not been found in other regions or groups of countries.
} 
rethinking public policies that are eventually implemented during recessions (see Alesina et al., 2019). Moreover, these effects might particularly make themselves felt in the countries most affected by the crisis where we find no clear positive effect of growth, although the period we use was characterized by the fact that the recovery was not very strong in these countries.

Finally, we can also relate our results with the reference levels of happiness, or set points, studied by the literature on happiness economics. Our results indicate that recessions can modify these references downwards, preventing a reversion to the average during recovery, in line with works such as Simandan's (2014). This exploratory hypothesis opens up a line of future research that can seek to ascertain what effects recessions have on individuals' reference levels of well-being in an effort to gain a deeper insight into the implications of the cycle and the stabilisation policies employed to deal with it. To this end, it is necessary to extend the analysis to include longer time periods as well as other types of economies in order to see whether asymmetries are repeated and, if so, to determine which factors might explain them.

Supplementary Information The online version contains supplementary material available at https://doi. org/10.1007/s10902-021-00401-5.

Funding The authors certify that they do not have any type of commercial, labor, financial or other relationship or particular interests that may have direct or potential influence or generate biases in this work.

\section{Declarations}

Conflict of interest The authors certify that they have NO affiliations with or involvement in any organization or entity with any financial interest (such as honoraria; educational grants; participation in speakers' bureaus; membership, employment, consultancies, stock ownership, or other equity interest; and expert testimony or patent-licensing arrangements), or non-financial interest (such as personal or professional relationships, affiliations, knowledge or beliefs) in the subject matter or materials discussed in this manuscript.

Human and Animal Rights This manuscript does not contain any studies with human or animal participants conducted by any of the authors.

Informed consent For this type of study, formal consent is not required.

\section{References}

Alesina, A., Favero, C., \& Giavazzi, F. (2019). Austerity. Princeton University Press, Princeton and Oxford. Apergis, N., \& Georgellis, Y. (2014). Does happiness converge? Journal of Happiness Studies, 16(1), 67-76

Baumeister, R., Bratslavsky, E., Finkenauer, C., \& Vohs, K. (2001). Bad is stronger than good. Review of General Psychology, 5(4), 323-370

Beja, E. (2017). The asymmetric effects of macroeconomic performance on happiness: Evidence for the EU. Intereconomics, 52(3), 184-190

Bonasia, M., Napolitano, O., \& Spagnolo, N. (2018). Happy PIIGS? Journal of Happiness Studies, 19(6), $1763-1782$

Case, A., \& Deaton, A. (2017). Mortality and morbidity in the 21 st century. Brookings papers on economic activity, BPEA Conference Drafts, March 23-24.

De Neve, J., Ward, G., De Keulenaer, F., Van Landeghem, B., Kavetsos, G., \& Norton, M. (2018). The asymmetric experience of positive and negative growth: Global evidence from subjective well-being data. Review of Economics and Statistics, 100(2), 362-375

Deaton, A. (2012). The financial crisis, the well-being of americans. Oxford Economic Papers, 64(1), 1-26 
DeCoster, J., Galluci, M., \& Iselin, A.-M. (2011). Best practices for using median splits, artificial categorization, and their continuous alternatives. Journal of Experimental Psychopathology, 2(2), 197-209

Di Tella, R., MacCulloh, R., \& Oswald, A. (2003). The macroeconomics of happiness. The Review of Economics and Statistics, 85(4), 809-827.

Easterlin, R. (1974). Does economic growth improve the human lot? In P. A. David \& M. W. Reder (Eds.), Nations, households in economic growth: Essays in honor of Moses Abramovitz. (pp. 89-125). Academic Press.

Eurostat. (2020). Database. https://appsso.eurostat.ec.europa.eu/nui/show.do?dataset=namq_10_gdp\& lang=en [Retrieved May 15, 2020].

Ferrer-i-Carbonell, A., \& Frijters, P. (2004). How important is methodology for the estimates of the determinants of happiness. The Economic Journal, 114, 641-659

GESIS (several years): Eurobarometer Data Service. https://www.gesis.org/eurobarometer-data-service/ search-data-access/data-access [Retrieved May 18, 2020].

Gonza, G., \& Burger, A. (2017). Subjective well-being during the 2008 economic crisis: Identification of mediating and moderating factors. Journal of Happiness Studies, 18(6), 1763-1797

Graham, C., \& Nikolova, M. (2015). Bentham or aristotele in the development process? An empirical investigation of capabilities and subjective well-being. World Development, 68, 163-179

Guardiola, J., \& Guillen-Royo, M. (2013). From Market needs to human needs: Spain, the economic crisis. FEG working paper series 02/13, faculty of economics, business (University of Granada).

Hirschauer, N., Lehberger, M., \& Musshoff, O. (2015). Happiness and utility in economic thought-or: What can we learn from happiness research for public policy analysis and public policy making? Social Indicators Research, 121(3), 647-674

Inglehart, R., Haerpfer, C., Moreno, A., Welzel, C., Kizilova, K., Diez-Medrano, J., Lagos, M., Norris, P., Ponarin, E., Puranen, B., et al. (Eds.). (2014). World values survey: Round six - country-pooled datafile version: www.worldvaluessurvey.org/WVSDocumentationWV6.jsp.

Kahneman, D., \& Krueger, A. (2006). Developments in the measurement of subjective well-being. Journal of Economic Perspectives, 20(1), 3-24

Kahneman, D., \& Tversky, A. (1974). Judgement under uncertainty: Heuristics and biases. Science, 185, 1124-1131

Kahneman, D., \& Tversky, A. (1981). The framing of decisions, the psychology of choice. Science, 211, $453-458$

Krueger, A., \& Schkade, D. (2008). The reliability of subjective well-being measures. Journal of Public Economics, 92(8-9), 1833-1845

Mertens, A., \& Beblo, M. (2016). Self-reported satisfaction, the economic crisis of 2007-10: Or how people in the UK, Germany perceive a severe cyclical downturn. Social Indicators Research, 125(2), 537-565

OECD. (2013). OECD guidelines on measuring subjective well-being. OECD Publishing.

Radcliff, B. (2013). Political economy of human happiness. Cambridge University Press.

Simandan, D. (2014). Omitted variables in the geographical treatment of well-being and happiness. Geography Journal, 2014, 1-5

Stone, A. A., \& Mackie, C. (2013). Subjective well-being: Measuring happiness, suffering, and other dimensions of experience. National Academic Press.

Tay, L., \& Diener, E. (2011). Needs and subjective well-being around the world. Journal of Personality and Social Psychology, 101(2), 354-365

van Praag, B. M. S., \& Ferrer-i-Carbonell, A. (2006). An almost integration-free approach to ordered response models. Tinbergen Institute Discussion Papers 06-047/3, Tinbergen Institute.

von Neumann, J., \& Morgenstern, O. (1944). Theory of games and economic behaviour. Princeton University Press.

Weckroth, M., Kemppainen, T., \& Dorling, D. (2017). Socio-economic stratification of life satisfaction in ireland during an economic recession: A repeated cross-sectional study using the european social survey. Irish Journal of Sociology, 25(2), 128-149

World Bank. (2020). DataBank. World Development Indicators. https://databank.worldbank.org/reports. aspx? source=world-development-indicators [Retrieved Sept 8, 2020].

Publisher's Note Springer Nature remains neutral with regard to jurisdictional claims in published maps and institutional affiliations. 